\title{
A Fuzzy Logic based Dynamic Voltage Restorer for Voltage Sag and Swell Mitigation for Industrial Induction Motor Loads
}

\author{
Md. Riyasat Azim \\ Dept. of EEE, Islamic \\ University of Technology, \\ Boardbazar, Gazipur-1704, \\ Bangladesh.
}

\author{
Md. Ashraful Hoque \\ Dept. of EEE, Islamic \\ University of Technology, \\ Boardbazar, Gazipur-1704, \\ Bangladesh.
}

\begin{abstract}
Power quality has been an issue that is becoming increasingly pivotal in industrial electricity consumers point of view in recent times. Modern industries employ Sensitive power electronic equipments, control devices and non-linear loads as part of automated processes to increase energy efficiency and productivity. Voltage disturbances are the most common power quality problem due to this increased use of a large numbers of sophisticated and sensitive electronic equipment in industrial systems. The Dynamic Voltage Restorer (DVR) has recently been introduced to protect the sensitive industrial loads from the detrimental effects of voltage sags/swells and other voltage disturbances. Configurations and control schemes for the DVR varies depending upon the nature and characteristics of the load to be protected. Industries with induction motors loads require a complete different approach for the design and control of a suitable DVR owing to the inherit inertia of the induction motors and their capability to withstand short-duration, shallow sags/swells, in addition to its tolerance to phase angle jumps. In this paper, a DVR with fast response, simple and efficient controller is proposed for fulfilling the voltage restoration requirements for industrial induction motor loads. The proposed DVR employs the classical Fourier Transform (FT) for sag/swell detection and quantification and a Fuzzy Logic based feedback controller which utilizes the error signal (difference between the reference voltage and actual measured load voltage) to control the triggering of the switches of an inverter using a Sinusoidal Pulse Width Modulation (SPWM) scheme. The proposed DVR utilizes the energy from available supply line feeders through a rectifier to feed the inverter. Modeling and simulation of the proposed DVR is implemented in MATLAB/SIMULINK platform. Simulation results have shown that the proposed DVR was efficient in mitigating balanced, unbalanced, multistage and consecutive sags, as well as swells.
\end{abstract}

\section{General Terms}

Control, Power Quality Enhancement, Design, Simulation and Experimentation.

\section{Keywords}

DVR, Power Quality, Voltage Sag, Voltage Swell, Fuzzy Logic Controller, MATLAB/SIMULINK.

\section{INTRODUCTION}

Power quality and reliability in distribution systems have been attracting an increasing interest in modern times and have become an area of concern for modern industrial and commercial applications. Introduction of sophisticated manufacturing systems, industrial drives, precision electronic equipments in modern times demand greater quality and reliability of power supply in distribution networks than ever before. Power quality problems encompass a wide range of phenomena. Voltage sag/swell, flicker, harmonics distortion, impulse transients and interruptions are a prominent few. These disturbances are responsible for problems ranging from malfunctions or errors to plant shut down and loss of manufacturing capability. Voltage sags/swells can occur more frequently than any other power quality phenomenon. These sags/swells are the most important power quality problems in the power distribution system [1].

Voltage Sag or Voltage Dip (IEC term) is defined by the IEEE 1159 as the decrease in the RMS voltage level to $10 \%-90 \%$ of nominal, at the power frequency for durations of $1 / 2$ cycle to one minute [2]. The IEC terminology for voltage sag is dip. The IEC defines voltage dip as a sudden reduction of the voltage at a point in the electrical system, followed by voltage recovery after a short period, from half a cycle to a few seconds [3]. According to IEEE 1159-1995 voltage sag amplitude of voltage sag is the value of the remaining voltage during the sag. Sag (dip) threshold magnitude specified for the purpose of detecting the start and the end of voltage sag (dip) which is defined to be $0.9 \mathrm{pu}$ as defined by IEC 1000-4-30. Generally the sag magnitude ranges from 0.1 to $0.9 \mathrm{pu}[2,3]$. Voltage sags are usually associated with system faults but they can also be generated by energization of heavy loads or starting of large motors which can draw 6 to 10 times its full load current during starting. Sag durations are subdivided into three categories, instantaneous, momentary, and temporary-all of which coincide with utility device operation times $[4,5]$.

Voltage Swell is defined by IEEE 1159 as the increase in the RMS voltage level to $110 \%-180 \%$ of nominal, at the power frequency for durations of $1 / 2$ cycles to one minute [2]. It is classified as a short duration voltage variation phenomena, which is one of the general categories of power quality problems. The term "momentary overvoltage" is used as a synonym for the term swell. According to IEEE 1159-1995, voltage swell magnitude is to be described by its remaining 
voltage, which is always greater than $1.0 \mathrm{pu}$. Voltage magnitude specified for the purpose of detecting the start and the end of a swell is known as swell threshold which is defined to be $1.1 \mathrm{pu}$ as defined by IEC 1000-4-30.Generally the swell magnitude ranges from 1.1 to $1.8 \mathrm{pu}[2,3]$. Like sags, swells are associated with system fault conditions but are not as common as sags. Swells can occur from the temporary voltage rise on the healthy phases during a single-line-to-ground (SLG) fault. Swells can also be caused by switching off a large load or energizing a large capacitor bank and are characterized by their magnitude (rms value) and duration. The severity of a voltage swell is a function of the fault location, system impedance and grounding $[4,5]$.

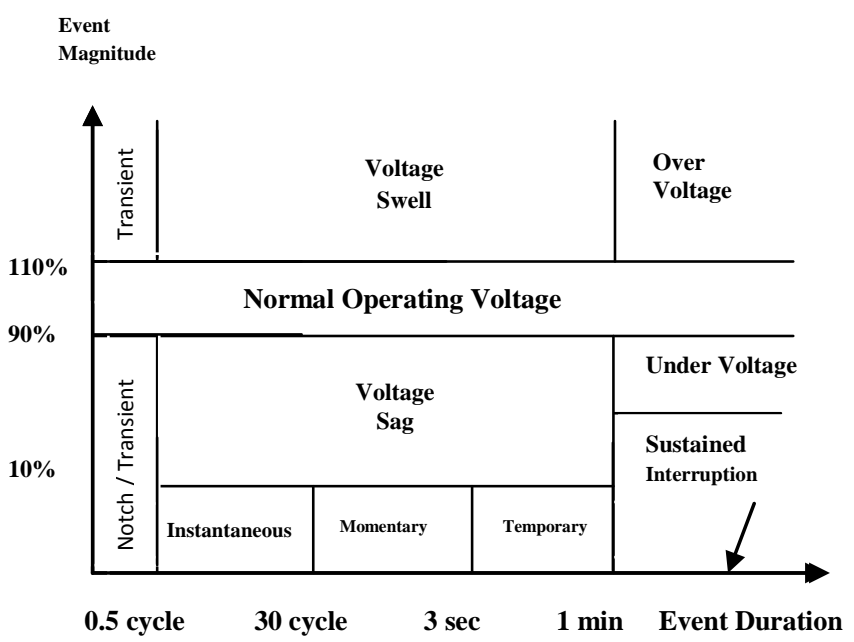

Fig 1: Voltage Reduction Standard of IEEE Std. 1159-1995

To calculate the voltage sag/swell magnitude at the Point of Common Coupling (PCC) in radial systems (which is the most prevailing one in industrial distribution networks), it is common to use the voltage divider model, shown in Fig 2, where the voltage magnitude at the $\mathrm{PCC}$ is given by:

$$
U_{\text {sag } / \text { swell }}=\frac{Z_{f}}{Z_{S}+Z_{f}}
$$

Where:

$\mathrm{Z}_{\mathrm{s}}=$ The source impedance including the transformer impedance

$\mathrm{Z}_{\mathrm{f}}=$ The impedance between the PCC and the fault including fault and line impedances [6]

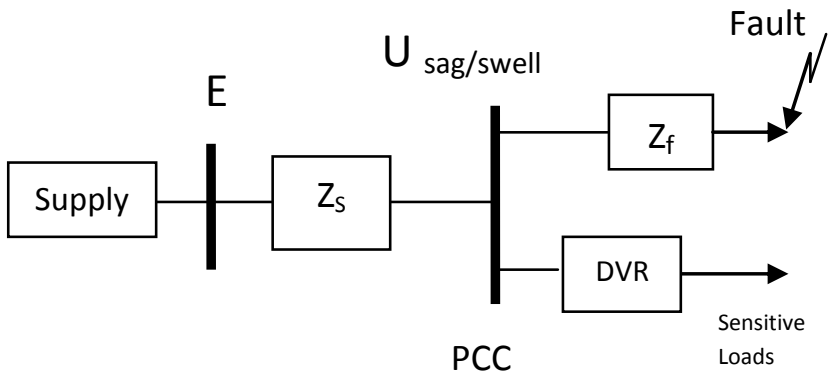

Fig 2: Faults on Parallel Feeders Causing Voltage Sag/Swell

As the quality of power is strictly related to the economic consequences associated with the equipment and should therefore be evaluated considering the customers point of view. So the need for solutions dedicated to single customers with highly sensitive loads is great since a fast response of voltage regulation is required. Further it needs to synthesize the characteristics of voltage sags/swells both in domestic and industrial distributions [7, 8]. Alongside the variation in magnitudes, voltage sags/swells can also be accompanied by a change in phase angle. This phenomenon is known as phase angle jump (i.e. the variation of phase angle before the onset and during the voltage sag/swell events and is calculated as an argument of the complex voltage) [9]. Phase angle jumps can also be detrimental for the cases of sensitive devices. In order to meet these challenges, it needs a device capable of injecting minimum energy so as to regulate load voltage at its predetermined value.

Dynamic Voltage Restorer (DVR) is one of the prominent methods for compensating the power quality problems associated with voltage sags/swells. Dynamic voltage restorer (DVR) can provide an effective solution to mitigate voltage sag/swell by establishing the appropriate predetermined voltage level required by the loads. It is recently being used as the active solution for voltage sag/swell mitigation in modern industrial applications. Induction Motors are the most widely used motors in modern industrial applications because of their relatively inexpensive rudimentary design, reliable operation and low maintenance costs. Induction motors are generally robust, but they can be susceptible to inadequate of improper operating voltages causing problems ranging from loss of quality to complete plant shutdowns. Voltage sags/swells have been identified as the pivotal cause for tripping of large induction motors in industrial systems. Studies on the effects of voltage sags/swells on Induction Motors demonstrated that IMs are insensitive to very short duration sags (and interruptions) or swells. IMs were also unaffected by phase angle jumps associated with most of the voltage sags/swells [10].

This study proposes a new configuration of Dynamic Voltage Restorer (DVR) with fuzzy logic based feedback controller capable of compensating for power quality problems associated with voltage sags/swells and maintaining a prescribed level of supply voltage at the induction motor load terminals. The simulation of the proposed DVR is accomplished using MATLAB/SIMULINK simpower systems toolbox. The performance of the proposed DVR for different supply disturbances is tested under various operating conditions. The simulation results have shown that the proposed DVR is capable of mitigating both balanced and unbalanced voltage sags/swells with acceptable efficiency and reliability.

\section{DYNAMIC VOLTAGE RESTORER}

Dynamic Voltage Restorer (DVR) is a series connected device capable of regulating the load side voltage in a distribution network. The DVR provides a three phase independently controlled voltage source utilizing power electronic components, whose voltage vector (magnitude and angle) is added to the source voltage to restore the load voltage to a prescribed level [11]. The main function of DVR is the protection of sensitive loads from voltage sags/swells arising from the distribution network. Thus it is generally installed in a distribution system between the supply and the sensitive load feeders [12]. In addition to voltage sags and swells compensation, DVR can also be used for line voltage harmonics compensation, voltage transients reductions and fault current limitations. Various 
circuit topologies and control schemes are available that can be used to implement a DVR.

\subsection{Configuration of DVR}

The general configuration of the DVR consists of an Injection transformer, a Harmonic filter, a Voltage Source Converter (VSC), Energy Storage Unit and a Control and Protection unit as shown in Fig 3.

Energy Storage Unit in DVR can be external batteries or capacitors charged from the supply line feeder through a rectifier. Generally the energy storage unit of a DVR can be divided into two parts (i.e. Storage devices and DC Charging Circuit). The purpose of energy storage devices is to supply the necessary energy to the VSC via a dc link for the generation of injected voltages.

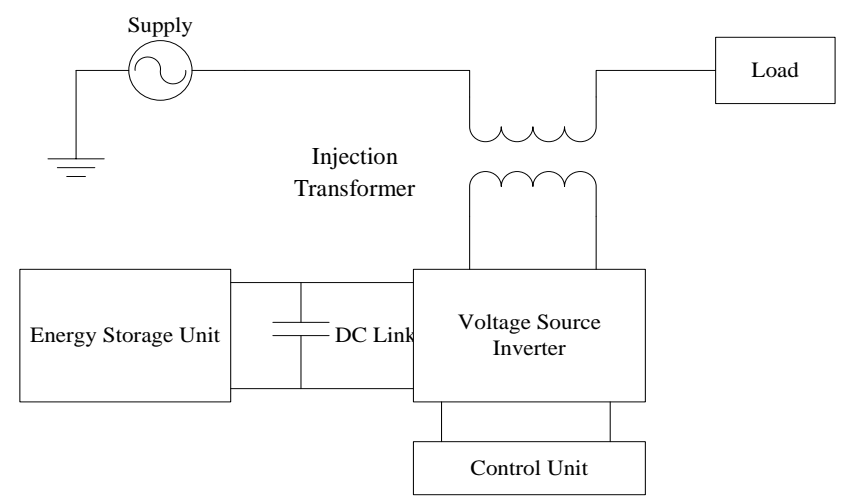

Fig 3: Schematic Diagram of DVR Configuration

The different kinds of energy storage devices are superconductive magnetic energy storage (SMES) [13], batteries, and capacitors $[14,15]$. In fact, the capacity of the stored energy directly determines the duration of the sag which can be mitigating by the DVR. Batteries are the common choice and can be highly effective if a high voltage battery configuration is used [16]. However, batteries in general have a short lifetime and often require some type of battery management system, which can be quite costly [17]. An interesting alternative to batteries is the use of supercapacitors, which have a wider voltage range than batteries and can be directly paralleled across the input bus. Supercapacitors have a specific energy density less than that of a battery, but a specific power greater than a battery, making them ideal for short (up to several seconds) pulses of power. Certain supercapacitors can hold charge over extended periods of time, so as to act like a battery. However, unlike batteries, these supercapacitors have a short charging time and much longer lifetime [14, 15]. The purpose of the DC Charging Circuit is to charge the energy storage devices after the compensation of a voltage sag/swell event as well as maintain a nominal dc link voltage. The charging circuit can be an external power supply or a rectifier fed from the supply mains of the distribution network.

A Voltage Source Converter is a power electronic system capable of generating a sinusoidal voltage at any required frequency, magnitude, and phase angle. DVR configurations use the VSC to generate the voltage required to compensate for the voltage sag/swell events $[18,19]$. Since the majority of the voltage sags/swells observed on distribution systems are unbalanced, the VSC will often be required to operate with unbalanced switching functions for the three phases and must therefore be able to treat each phase independently. Moreover, sag on one phase may result in swell on another phase, so the VSC must be capable of handling both sags and swells simultaneously. The output voltage of the inverter is varied by using different PWM schemes available.

Given to the nonlinear nature of the semiconductor devices Voltage waveform distortion associated with the high frequency harmonics at the output of the inverter circuit is a common phenomenon. A harmonic filter unit is generally used at the output of the inverter circuit to keep the harmonic distortions at a permissible level. Although the filter unit keeps the harmonic distortion minimum and improves the quality of the generated voltage, it can also introduce voltage drop and phase shift in the fundamental component of the inverter output and needs to be accounted for in the generated compensation voltage [20].

Injection transformers are responsible for connecting the DVR to the sensitive loads in the distribution network via the high tension windings and transforming and coupling of the injected compensating voltages generated by the voltage source converters to the incoming supply voltage. In addition, the Injection transformer also serves the purpose of isolating the load from the system (VSC and control mechanism). Generally three single-phase transformers are used as injection transformers for injecting the compensating voltages to the system at the load bus. Proper integration of the injection transformer into the DVR, the MVA rating, the primary winding voltage and current ratings, the turn-ratio and the short-circuit impedance values of transformers are required. The existence of the transformers allow for the design of the DVR in a lower voltage level, depending upon the stepping up ratio. In such case, the limiting factor will be the ability of the inverter switches to withstand higher currents [21].

The control unit of DVR is solely responsible for controlling the compensating voltage generation by controlling the PWM pulses to the gates of semiconductor switches of the VSC. To maximize dynamic performance of DVR, efficient control architecture capable of achieving fast compensation is necessary $[22,23]$. The protection unit of DVR generally consists of Bypass switches, breakers, measuring and protection relays etc. Depending upon the operating conditions, the control and protection unit maximizes the system performance and minimizes the losses associated with the operation of DVR.

\subsection{Compensation Methods}

Compensation of voltage sags/swells is dependent upon a number of factors including DVR power rating, different load conditions and different types of voltage sags/swells. Some loads are very sensitive to phase angle jump while others are tolerant to it. Therefore, the compensation strategy depends upon the type and characteristics of the load connected to DVR. There are three different methods for DVR voltage injection which are presented below.

\subsubsection{Pre-Fault Compensation}

The DVR injects the difference voltage between during fault and pre-fault voltages to the system. In this method the DVR compensates for both magnitude and Phase angle. The main drawback of this technique is it requires a higher capacity energy storage device [23]. Fig 4a shows the vector diagram for 
the pre-fault control strategy for a voltage sag event. This method is best suited to loads sensitive to phase angle jumps as it compensates for both the magnitude and phase angle.

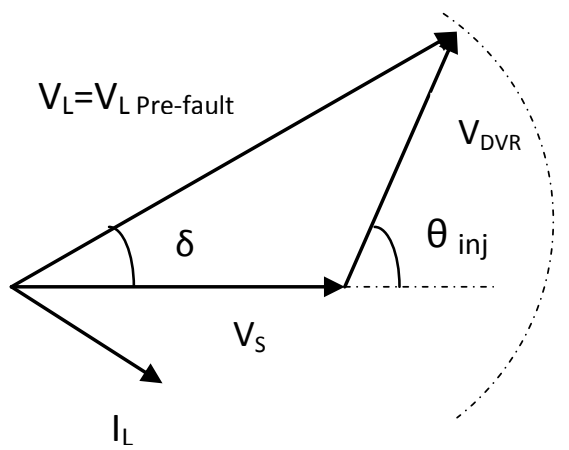

Fig 4a: Compensation to pre-fault conditions for a voltage sag event (magnitude and phase)

In this diagram, $\mathrm{V}_{\text {pre-fault }}$ and $\mathrm{V}_{\text {Sag }}$ are voltage at the point of common coupling (PCC), respectively before and during the sag. In this case $V_{D V R}$ is the voltage injected by the DVR, which can be obtained as:

$$
V_{D V R}=\sqrt{V_{L}^{2}+V_{S}^{2}-2 V_{L} V_{S} \cos \delta}
$$

and the required angle of injection $\theta_{\text {inj }}$ is calculated as:

$$
\theta_{\text {inj }}=\tan ^{-1} \frac{V_{S} \sin \delta}{V_{S} \cos \delta-V_{L}}
$$

A closer look at Fig 4a shows that, in normal conditions (prefault), the system or supply voltage is equal to the load voltage $\mathrm{V}_{\mathrm{L}}$, both are equal to 1 p.u. with zero angle. During sag, the system voltage decreases to a value $\mathrm{V}_{\mathrm{s}}$ less than 1 p.u., this reduction in voltage is associated with a phase angle jump $\delta$. The DVR reacts to the sag event and injects a compensating voltage $\mathrm{V}_{\mathrm{DVR}}$ to restore the voltage at the load to pre-fault conditions of both magnitude and angle. The method gives nearly undisturbed load voltage $[21,23]$.

\subsubsection{In Phase Compensation}

In Phase compensation technique is designed to compensate for the voltage magnitude only. In this method jumps in the phase angle is not compensated $[23,24]$.

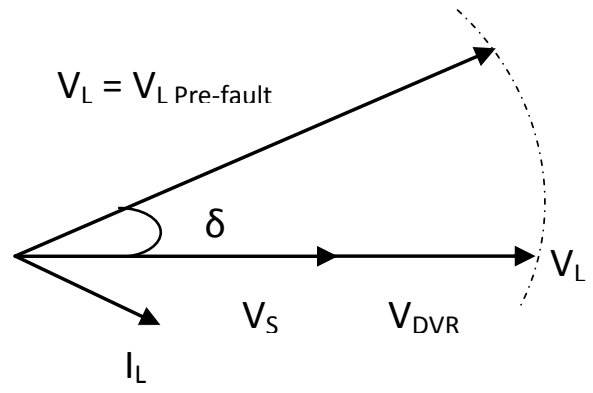

Fig 4b: In Phase Compensation to pre-fault conditions for voltage sag event (magnitude only)

The vector diagram corresponding to In Phase Compensation method is shown in Fig 4b. Here, the pre-fault voltage is 1 p.u. with zero angle and during sag, the system voltage decreases to
$\mathrm{V}_{\mathrm{S}}$ with a phase angle $\delta$. The DVR injects a compensating voltage $V_{D V R}$ in phase with the system voltage $V_{S}$, to boost the voltage magnitude up to the pre-fault voltage magnitude $\mathrm{V}_{\mathrm{L}}$, with no attention to the angle $\delta$. This method is suitable for loads that can withstand phase angle jumps, which is a typical case for induction motor loads which comprise a large portion of the industrial power system, with no sensitive equipment such as adjustable speed drives or any equipment depending in its operation on phase triggered switches. This method is very simple in implementation, very fast especially in calculating the DVR compensation voltage, which is obviously calculated as:

$$
\left|V_{D V R}\right|=\left|V_{L}\right|-\left|V_{S}\right|
$$

\subsubsection{In Phase Advanced Compensation}

Pre-fault compensation and in-phase compensation must inject active power to loads almost all the time. Due to the limit of energy storage capacity of DC link, the DVR restoration time and performance are confined in these methods.

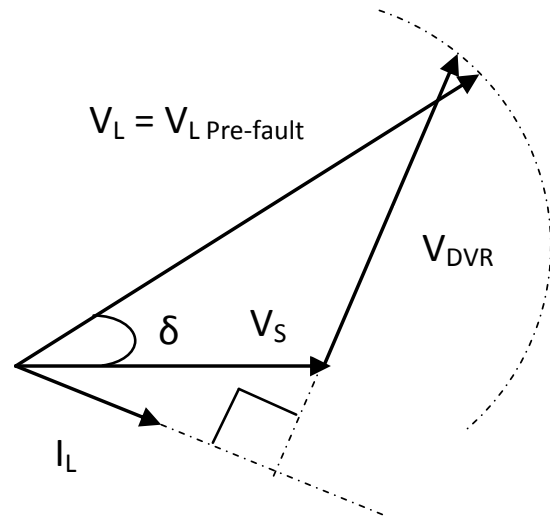

Fig 4c: In Phase Advanced Compensation to pre-fault conditions for voltage sag event.

The fundamental idea of in phase advanced compensation method is to make injection of active power zero. In order to minimize the use of real power the voltages are injected at $90^{\circ}$ phase angle to the supply current. Fig $4 \mathrm{c}$ shows the vector diagram to describe the In Phase Advanced Compensation method [25].

\subsection{Operation Modes of DVR}

The operation of Dynamic Voltage Restorer (DVR) can be categorized into three modes namely protection mode, standby mode and injection mode. In protection mode of operation DVR is protected from the over current in the load side due to short circuit on the load or large inrush currents. Bypass switches are used to separate the DVR from the system in protection mode. Generally DVR operates in standby mode in normal steady state conditions. In this mode of operation, the DVR may either be bypassed or inject small voltage to compensate the voltage drop on transformer reactance or losses. DVR is generally bypassed because the small voltage drops do not disturb the load requirements if the distribution circuit is not too weak. DVR enters the injection mode of operation as soon as an abnormality is detected in load side voltage. DVR injects a three phase compensating voltage with each of the three phases having independently controlled magnitude and phase to meet the requirements on that particular phase. The DVR should ensure 
the unchanged load voltage with minimum energy dissipation for injection due to the high cost of capacitors [26].

\subsection{Control Methods for DVR}

DVR Control strategies fall mainly in one of the two categories namely linear control methods and Non-linear control methods. Linear control methods can be employed with the feedback, the feed-foreword and the combined feed controllers. Non-Linear control methods comprising the Artificial Neural Networks (ANN), the Fuzzy Logic (FL) and the Space Vector (SV) controllers Although feedback controllers are popular, they require load and source tracking, whereas feed-foreword controllers are much simpler yet open-looped, there is no feedback from the load voltage or current [22-24].

The proposed DVR utilizes capacitors as the energy storage units fed through the supply mains via the rectifier. The compensation strategy is chosen to be the in phase compensation method due to its simplicity of implementation and induction motor no being sensitive to phase angle jumps. And the control of the proposed DVR is based on a fuzzy logic based feedback controller.

\section{MATERIALS AND METHODS}

This study proposes a fuzzy logic controlled DVR with in-phase compensation strategy for voltage sag/swell compensation for industrial induction motor loads. Since the in-phase compensation strategy is simpler and efficient, the operation of the proposed DVR is simpler and its response time is also faster. Fig 5 shows the block diagram of the proposed controller for the DVR.

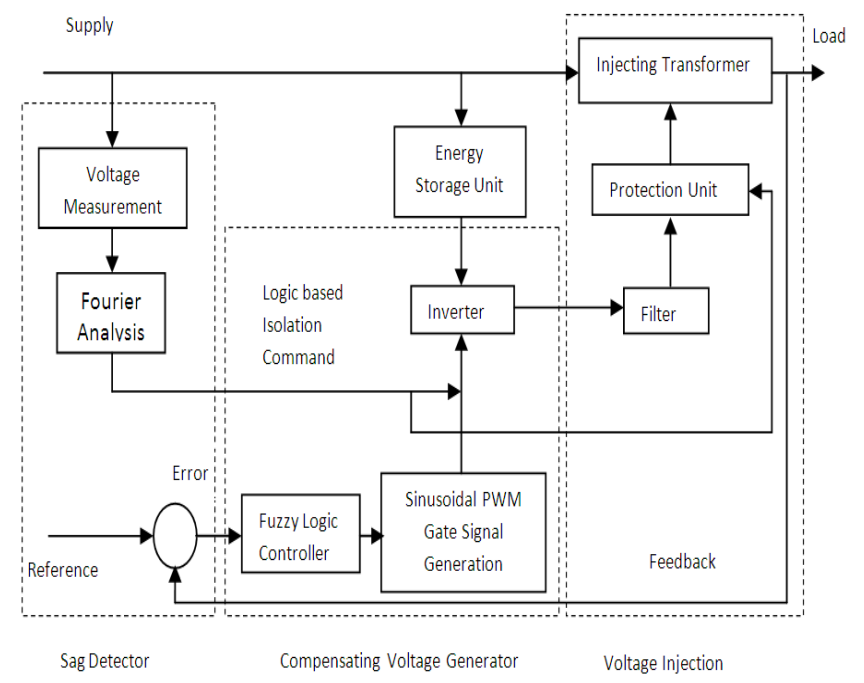

Fig 5: Block diagram of the proposed DVR control scheme.

The controller of the proposed DVR consists of the following blocks:

\subsection{Detection of Sag and Swell Events}

$\mathrm{Sag} / \mathrm{Swell}$ detection includes determination of the instants when a sag/swell event starts and ends, magnitude of the variation and the phase angle jumps. Several approaches for detection of sag/swell events available are Classical Fourier Transform method, Wavelet analysis, use of RMS values, use of peak values, the transformation of the three phase voltages to a two dimensional frame (dq frame) and therefore to one phasor etc. [21, 27].

In this study, the proposed DVR uses the traditional Fourier Transform method to detect the voltage sag/swell events. The Fourier transform based sag/swell detector associated with the proposed DVR can track the magnitude and the phase angle of the fundamental frequency component of the supply voltage simultaneously in order to make sure that the injected sine wave will be in-phase with the remaining sine wave during the sag/swell events, to have a constructive vector addition of the DVR and the supply voltages. Since the compensation strategy used in the proposed DVR is in-phase method, computation of the compensating voltage magnitude is done using a comparator with one input as the variable load voltage and the other being the reference voltage for each of the three phases independently. The output of the comparator determines the magnitude of the voltage required to be injected by the DVR and is called the error signal which is the input to the fuzzy logic based feedback controller used for controlling the output voltage of the inverter through the control of the modulation index for each of the three phases of the inverter independently.

\subsection{Compensating Voltage Generation}

The inverter circuit in DVR is responsible for generation of the compensating voltage. Hence the control of the inverter will directly affect the performance of the DVR. The inverter used in the proposed DVR is a three phase six pulse inverter. The thyristors used in the inverter circuit are chosen to be Insulated Gate Bipolar Transistors (IGBT) for their fast response and robust operation. The inverter uses Sinusoidal Pulse Width Modulation (SPWM) for controlling the modulation index hence controlling the output voltage of the inverter.
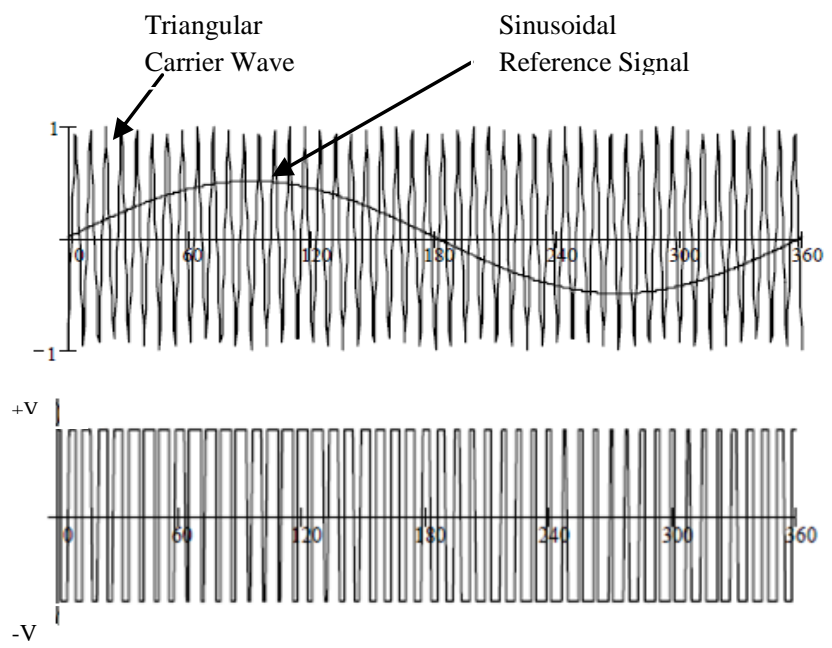

Fig 6: Sinusoidal Pulse Width Modulation Scheme.

In SPWM, a sinusoidal reference signal of supply frequency (i.e. $50 \mathrm{~Hz}$ ) is compared with a high frequency triangular carrier waveform (i.e. $1080 \mathrm{~Hz}$ for this study). When the sinusoidal reference signal is greater than the triangular carrier wave, a batch of three IGBT switches out of the six are turned on and the counter switches are turned off and when the reference sinusoidal signal is smaller than the triangular carrier waveform in magnitude then the second batch of three IGBT switches are turned on and the first batch of switches are turned off. The 
magnitude of the sinusoidal reference signal determines the modulation index of the PWM signal generator which is dependent upon the error signal. The magnitude of the sinusoidal reference signal is controlled by the fuzzy logic based feedback controller which adjusts the magnitude according to the error magnitude and hence control the modulation index. The proposed DVR utilizes large capacitor banks for storing dc energy. Supply line voltage is rectified and used to charge the capacitor banks. DC voltage from alternative supply sources can also be utilized with the proposed configuration of DVR.

\subsection{Fuzzy Logic Controller}

Fuzzy logic theory is considered as a mathematical approach combining multi-valued logic, probability theory, and artificial intelligence to replicate the human approach in reaching the solution of a specific problem by using approximate reasoning to relate different data sets and to make decisions. The performance of Fuzzy Logic Controllers is well documented in the field of control theory since it provides robustness to dynamic system parameter variations as well as improved transient and steady state performances.

In this study, a fuzzy logic based feedback controller is employed for controlling the voltage injection of the proposed Dynamic Voltage Restorer (DVR). Fuzzy logic controller is preferred over the conventional PI and PID controller because of its robustness to system parameter variations during operation and its simplicity of implementation. Since the proposed DVR uses energy storage system consisting of capacitors charged directly from the supply lines through rectifier and the output of the inverter depends upon the energy stored in the dc link capacitors. But as the amount of energy stored varies with the voltage sag/swell events, the conventional PI and PID controllers are susceptible to these parameter variations of the energy storage system; hence the control of voltage injection becomes difficult. The proposed FLC scheme exploits the simplicity of the Mamdani type fuzzy systems that are used in the design of the controller and adaptation mechanism.

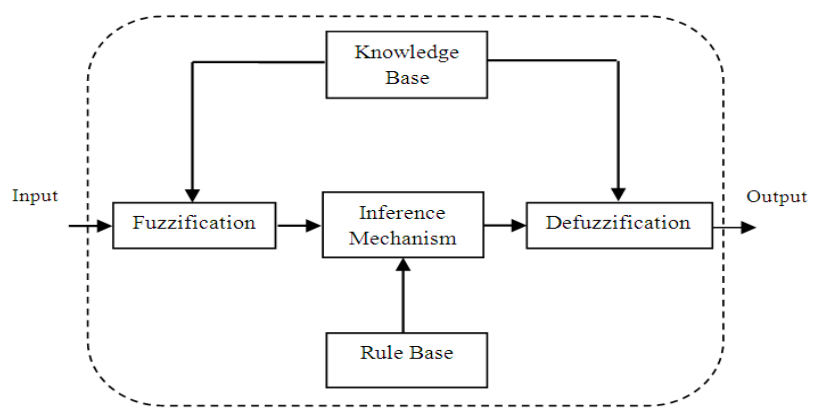

Fig 7: Schematic representation of Fuzzy Logic Controller.

The fuzzy logic based control scheme (Fig 7) can be divided into four main functional blocks namely Knowledge base, Fuzzification, Inference mechanism and Defuzzification. The knowledge base is composed of data base and rule base. Data base consists of input and output membership functions and provides information for appropriate fuzzification and defuzzification operations. The rule-base consists of a set of linguistic rules relating the fuzzified input variables to the desired control actions. Fuzzification converts a crisp input signals, error (e), and change in error (ce) into fuzzified signals that can be identified by level of memberships in the fuzzy sets. The inference mechanism uses the collection of linguistic rules to convert the input conditions to fuzzified output. Finally, the defuzzification converts the fuzzified outputs to crisp control signals using the output membership function, which in the system acts as the changes in the control input (u).

The typical input membership functions for error and change in error are shown in Fig 8a and Fig 8b respectively, whereas the output membership function for change in control input is shown in Fig 8c. The output generated by fuzzy logic controller must be crisp which is used to control the PWM generation unit and thus accomplished by the defuzzification block. Many defuzzification strategies are available, such as, the weighted average criterion, the mean-max membership, and center-of-area (centroid) method. The defuzzification technique used here is based upon centroid method.

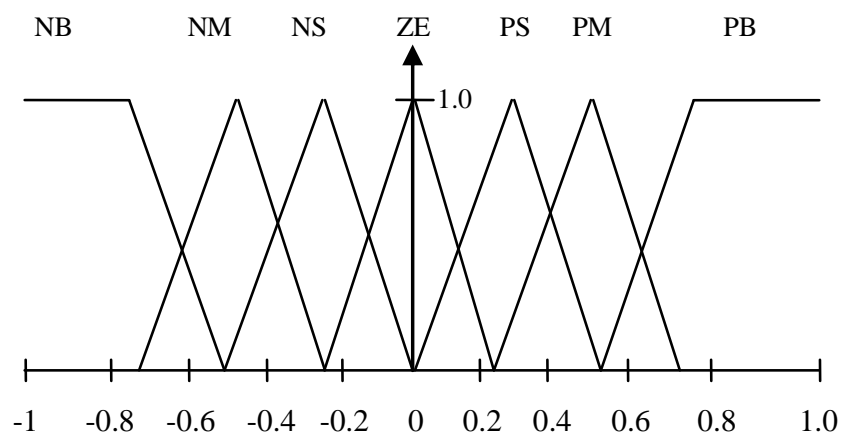

Fig 8a: Membership Function for Input Variable Error, 'e'.

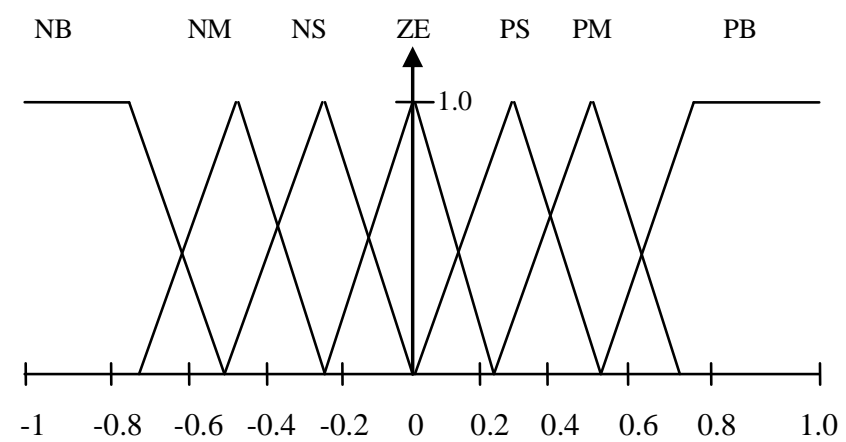

Fig 8b: Membership Function for Input Variable Change in Error, 'ce'.

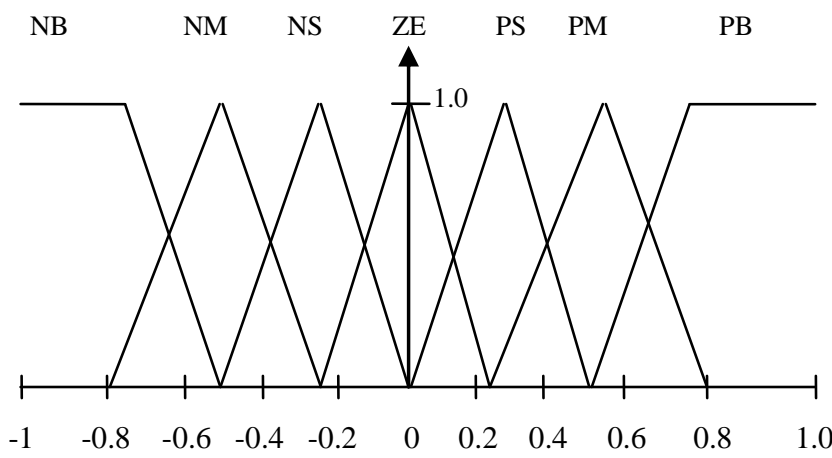

Fig 8c: Membership Function for Output Variable Change in Control Signal, ' $u$ '. 
The set of fuzzy control linguistic rules is given in Table 1. The inference mechanism of fuzzy logic controller utilizes these rules to generate the required output.

Table 1. Rule Base for Fuzzy Logic Controller

\begin{tabular}{|c|c|c|c|c|c|c|c|}
\hline $\begin{array}{c}\text { 'ce' } \\
\text { 'ce' }\end{array}$ & NB & NM & NS & ZE & PS & PM & PB \\
\hline NB & NB & NB & NB & NB & NM & NS & ZE \\
\hline NM & NB & NB & NB & NM & NS & ZE & PS \\
\hline NS & NB & NB & NM & NS & ZE & PS & PM \\
\hline ZE & NB & NM & NS & ZE & PS & PM & PB \\
\hline PS & NM & NS & ZE & PS & PM & PB & PB \\
\hline PM & NS & ZE & PS & PM & PB & PB & PB \\
\hline PB & ZE & PS & PM & PB & PB & PB & PB \\
\hline
\end{tabular}

DVR is generally connected in feeders having sensitive loads whose terminal voltage has to be regulated. The SIMULINK model of proposed fuzzy logic controller is shown in the Fig 9.

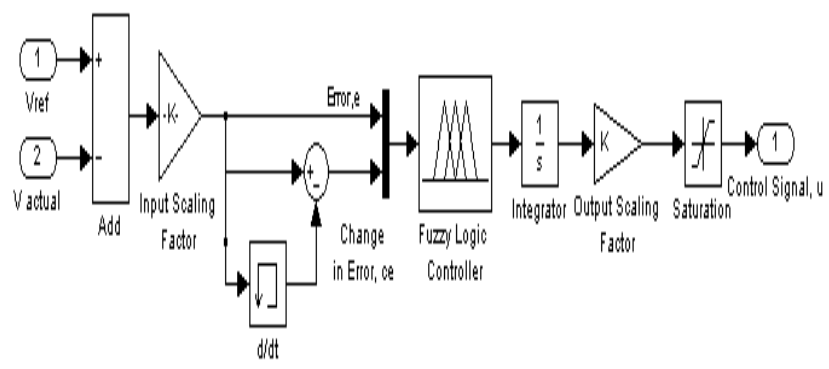

Fig 9: SIMULINK model of proposed FLC.

\section{MODELING AND SIMULATION}

The performance of the proposed fuzzy logic based DVR is evaluated by using MATLAB/SIMULINK program as a simulation platform. The DVR is connected in series between a three phase programmable (controllable) voltage source with $400 \mathrm{~V}$ line to line RMS voltage, $50 \mathrm{~Hz}$ and a load of active power $\mathrm{p}=10 \mathrm{KW}$ and reactive power $\mathrm{Q}=1 \mathrm{KVAR}$ (with installation of power factor correction capacitors). The Simulink model of the proposed DVR is shown in Fig 15.

\section{RESULTS AND DISCUSSIONS}

Results are obtained by simulating the proposed DVR system in MATLAB/SIMULINK software. The minimum operation time of the DVR is 1 cycle or 20 milliseconds. Several power quality phenomena associated with voltage sag and swell have been simulated and the results are arranged in the following sequence for all cases: (a) the supply voltage $\left(\mathrm{V}_{\text {Supply }}\right)$, (b) the DVR voltage $\left(\mathrm{V}_{\mathrm{DVR}}\right)$ and $(\mathrm{c})$ the load voltage $\left(\mathrm{V}_{\text {Load }}\right)$.

\subsection{Simulation Results}

\subsubsection{Three Phase Balanced Sag}

A three phase balanced voltage sag is simulated by reducing the line to line voltage on each phase to $60 \%$ of the normal value for a duration of 0.3 seconds from $t=0.4 \mathrm{sec}$ till $\mathrm{t}=0.7 \mathrm{sec}$ as shown in Fig 10. The simulation duration was 1 second.
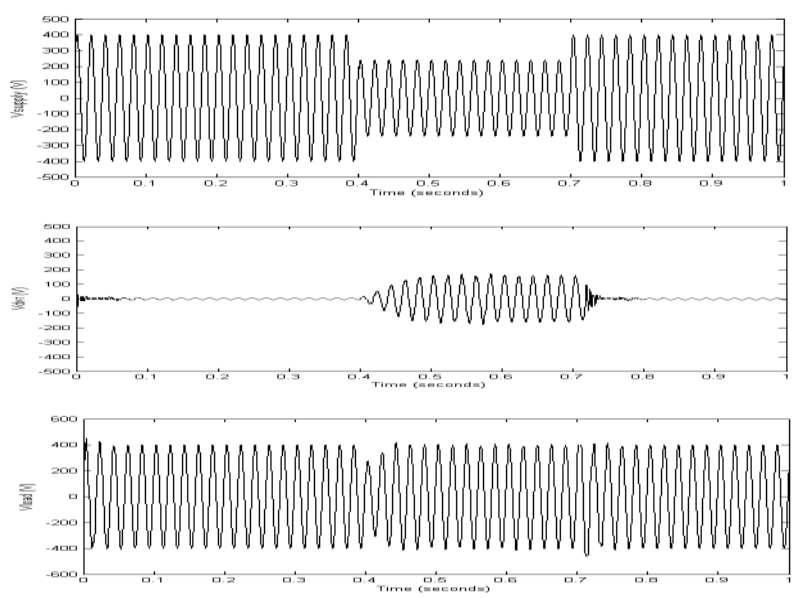

Fig 10: Three Phase Balanced Voltage Sag.

\subsubsection{Three Phase Balanced Swell}

A three phase balanced voltage swell is simulated by increasing the line to line voltage on each phase to $140 \%$ of the normal value for a duration of 0.3 seconds from $t=0.4 \mathrm{sec}$ till $\mathrm{t}=0.7 \mathrm{sec}$ as shown in Fig 11. The simulation time was 1 second.
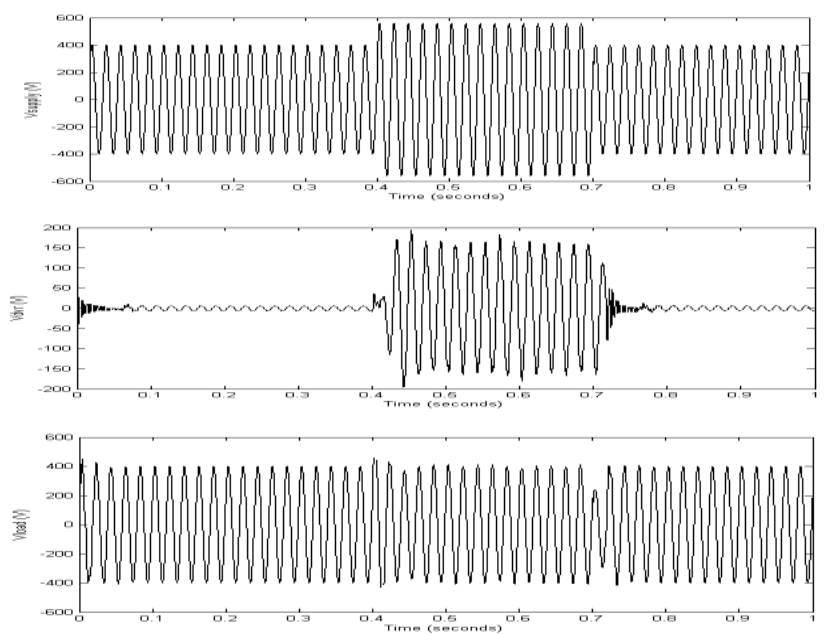

Fig 11: Three Phase Balanced Voltage Swell.

\subsubsection{Consecutive Sag and Swell}

Voltage sag on the three phases of $60 \%$ of the normal value is simulated on all of the three phases for $0.4 \mathrm{sec}$ starting from $\mathrm{t}=0.4 \mathrm{sec}$ and ending at $\mathrm{t}=0.8 \mathrm{sec}$ which is followed by $\mathrm{a}$ balanced three phase voltage swell of $140 \%$ of the normal voltage value for $t=0.4 \mathrm{sec}$ starting from $t=1.0 \mathrm{sec}$ to $t=1.4 \mathrm{sec}$. The duration of the simulation was 2 seconds and the results are shown in Fig 12. 

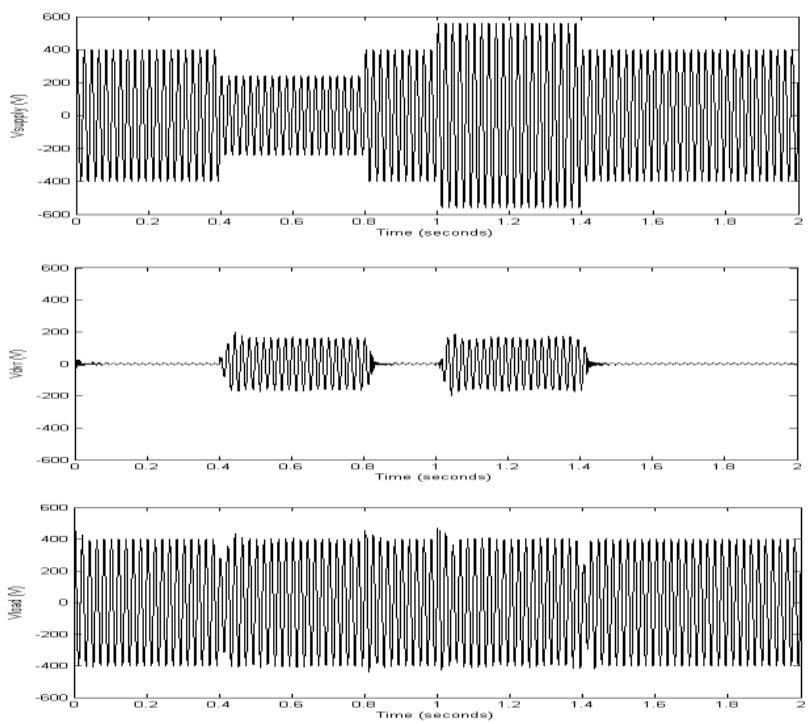

Fig 12: Consecutive Voltage Sag and Swell.

\subsubsection{Multi-stage Sag}

Voltage sags on the three phases at $50 \%$ of the normal value is simulated for $0.3 \mathrm{sec}$ from $\mathrm{t}=0.3 \mathrm{sec}$ till $\mathrm{t}=0.6 \mathrm{sec}$, after that, the sag prolonged on another stage at $60 \%$ of the normal voltage magnitude for $0.2 \mathrm{sec}$ from $\mathrm{t}=0.6$ to $\mathrm{t}=0.8$ as shown in Fig 13 . The duration of the simulation in this case was 1 second.
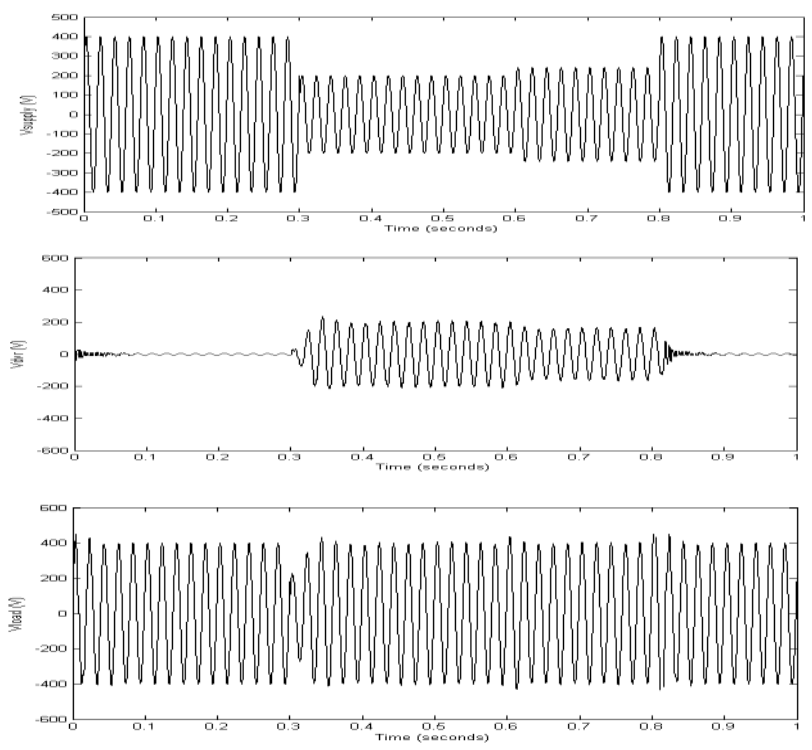

Fig 13: Multi-stage Voltage Sag.

\subsubsection{Three phase unbalanced sag}

Single-Line-To-Ground (SLG) faults are the most prevalent type of three phase unbalanced sags. For the purpose of the simulation, Phase A voltage magnitude is sagged to $50 \%$ for 0.5 sec from $t=0.3 \mathrm{sec}$ till $\mathrm{t}=0.7$. The line to line voltage magnitudes $\mathrm{V}_{\mathrm{AB}}$ and $\mathrm{V}_{\mathrm{CA}}$ will be affected but the magnitude of $\mathrm{V}_{\mathrm{BC}}$ will remain unchanged. The simulation time used was 1 second and the results are shown in Fig 14.
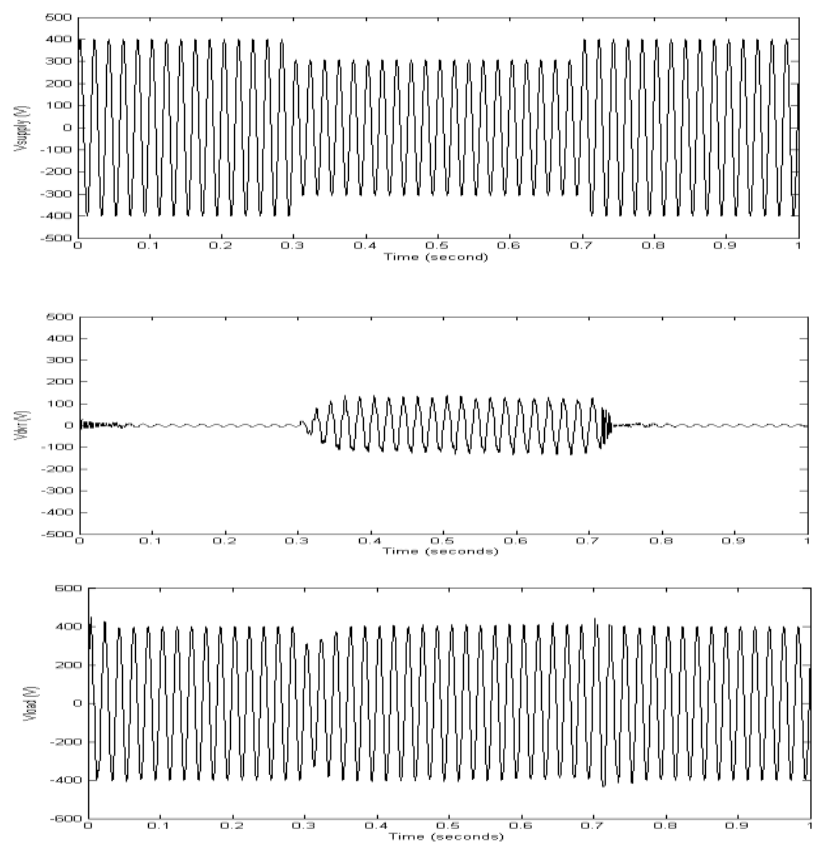

Fig 14: Three Phase Unbalanced Voltage Sag.

\section{CONCLUSION}

In this study, a simple, fast and efficient Dynamic Voltage Restorer (DVR) is proposed for mitigation of power quality problem associated with voltage sags/swells in industrial distribution systems with a large portion of its load comprising of induction motors. The proposed DVR employs the classical Fourier Transform technique for detection and quantification of voltage disturbances (sags/swells) events. Since induction motors are not sensitive to changes in phase angle, in phase compensation method is used for calculation of the compensating voltage since it is fast and simple and finally a fuzzy logic based feedback controller is used to control the voltage injection of the proposed DVR system in case of voltage disturbances. The proposed DVR utilizes energy drawn from the supply line source during normal operation and stores in capacitors and which is converted to an adjustable three phase ac voltage suitable for mitigation of voltage sags/swells. The modeling and simulation of the proposed DVR using MATLAB/SIMULINK had been presented. The simulation shows that the DVR performance is efficient and satisfactory in mitigating voltage sags/swells. The DVR handles both balanced and unbalanced situations with sufficient efficiency and accuracy and injects the appropriate voltage component to correct rapidly any deviation in the supply voltage to keep the load voltage constant at the nominal value.

The main advantages of the proposed DVR are simple and efficient adaptive control and fast response. Future works will include a comparison with a laboratory experiments on a low voltage DVR in order to compare simulation and experimental results and estimate the cost of the practical system. Further issues associated with low pass filter construction and its parameters selection, injection transformer selection and its saturation and reduction in operational time of the entire DVR system will be investigated in future works. 


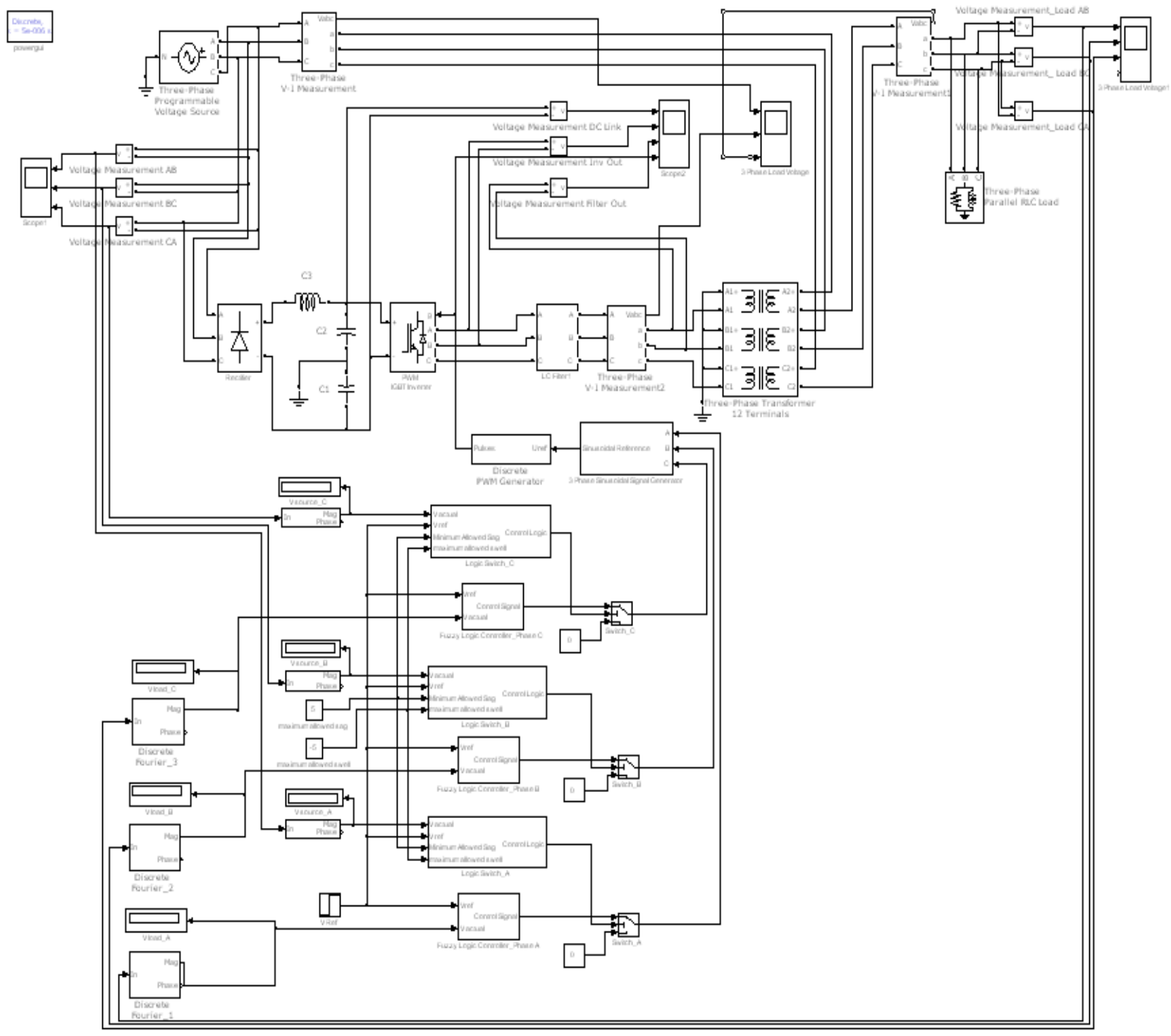

Fig 15: SIMULINK Model of the proposed DVR system

\section{REFERENCES}

[1] N.G. Hingorani, 1995, "Introducing Custom Power in IEEE Spectrum", 32p, pp 41-48.

[2] IEEE Std 1159-2001R, IEEE Recommended Practice for Power Quality Monitoring

[3] IEC 1000-4-30, Testing and Measurement Techniques Power Quality Measurement Methods

[4] Bingham, R., 1998, "SAGs and SWELLs". New Jersey: Dranetz-BMI

[5] Dugan, R., McGranaghan, M., Santoso, S., and Beaty, H.W. 2004. Electrical Power Systems Quality (2nd ed.). New York: McGraw-Hill.

[6] Bollen, M., 1996, Fast assessment methods for voltage sags in distribution systems. IEEE Trans. Ind. Appli., 32: 14141423.
[7] G. Yalcinkaya, M.H.J. Bollen and P.A. Crossley, July/Aug 1998, "Characteristics of voltage sags in industrial distribution systems," IEEE Trans on Industry Appl,, vol. 34 , no. 4, pp. 682-688.

[8] E.R.Collins Jr and S.W.Middlekauff, Jan 1998, System and customer impact: considerations for series custom power devices," IEEE Trans on Power Delivery, vol. 13, no. 1, pp. 278-282.

[9] Djokic, S. and J. Milanovic, 2006, Advanced voltage sag characterization. Part I: Phase shift. IEEE Proc. Generation. Transmission, Distribution, 153: 423-430. DOI: 10.1049/ip-gtd:20050350

[10] ElShennawy, T., M. El-Gammal and A. Abou-Ghazala, 2009. Voltage sag effects on the process continuity of a refinery with induction motors loads. Am. J. Applied Sci., 6: $1626-1632$ 
[11] Woodley, N., R. Morgan and A. Sundaram, 1999. Experience with an inverter-based dynamic voltage restorer. IEEE Trans. Power Delivery, 14: 1181-1185.

[12] Etxeberria-Otadui, I., U. Viscarret, S. Bacha, M. Caballero and R. Reyero, 2002. Evaluation of different strategies for series voltage sag compensation. Proceeding of the IEEE 33rd Annual Power Electronics Specialists Conference, June 23-27, Cairns, Queensland, Australia, pp: 1797-1802.

[13] C. Zhan, V.K. Ramachandaramurthy, A. Arulampalam, C. Fitzer, S. Kromlidis, M. Barnes, N. Jenkins, 2001, "Dynamic voltage restorer based on voltage space vector PWM control" in Proc. Applied Power Electronics Conference and Exposition, pp. 1301- 1307

[14] J. H. Han, II D. Seo, 1. G. Shon, H. j. jeon, 2007, 'Development of On-line type Dynamic Voltage Compensation System Using Supercapacitor', The 7th International Conference on Power Electronics October 2226, EXCO, Daegu, Korea.

[15] Y. Li, Y. 1. Wang, B. h. Zhang, C. x. Mao, 2008, 'Modeling and Simulation of Dynamic Voltage Restorer Based on Super Capacitor Energy Storage' International Conference on Electrical Machines and Systems (ICEMS), 17-20 Oct., pp.2064-2066, Wuhan, China.

[16] P. Jayaprakash, B. Singh, D. P. Kothari, A. Chandra, K. AlHaddad, 2008, 'Control of Reduced Rating Dynamic Voltage Restorer with Battery Energy Storage System', IEEE Power India Conference, 12-15 Oct., pp: 1-8, New Delhi, India.

[17] C. Zhan, M. Barnes, V.K. Ramachandarmurthy, N. JenkinsJ, 2000, Dynamic Voltage Restorer with Battery Energy Storage for Voltage Dip Mitigation, Power Electronics and Variable Speed Drives, 18-19 September, Conference Publication No. 475 0 IEE 2000

[18] W. J. Xu, A. S. Yueyue, 2008, 'A Survey on Control Strategies of Dynamic Voltage Restorer' 13th International Conference on Harmonics and Quality of Power (ICHQP), Sept. 28 -Oct. 1, pp: 1-5, Wollongong, NSW.
[19] J. G. Nielsen, F. Blaabjerg, 2005, A Detailed Comparison of System Topologies for Dynamic Voltage Restorers' IEEE transactions on industry applications, vol. 41, No.5, September October.

[20] H. Kim, J. H. Kim, S. K. Sul, 2004, "A design consideration of output filters for dynamic voltage restorers," Power Electronics Specialists Conference. PESC 04.2004 IEEE 35th Annual, Volume 6, 20-25 June 2004 Page(s):4268 - 4272 Vo1.6

[21] ElShennawy, Abdel-Mon'em Moussa, M. El-Gammal and A. Abou-Ghazala, 2010. "A Dynamic Voltage Restorer for Voltage Sag Mitigation in a Refinery with Induction Motor Loads", Am. J. Applied Sci. 3(1), 144-151, 2010.

[22] Jing, W., X. Aiqin and S. Yueyue, 2008. A survey on control strategies of dynamic voltage restorer.Proceeding of the IEEE 13th International Conference Harmonics and Quality of Power (ICHQP), Sept. 28-Oct. I, Wollongong, NSW., pp: 1-5. DOI: 10.1109/ICHQP.2008.4668845

[23] Meyer, C. Romaus, C. Doncker, R. W., 2005, “Optimized Control Strategy for a Medium-Voltage DVR". Power Electronics Specialists Conference, IEEE, pp: 1887-1993.

[24] Nielsen, J. G. Blaabjerg, F. and Mohan, 2005, N. "Control Strategies for Dynamic Voltage Restorer Compensating Voltage Sags with Phase Jump". Applied Power Electronics Conference and Exposition, IEEE, Vol.2 pp: $1267-1273$.

[25] Kim, H., 2002, "Minimal energy control for a dynamic voltage restorer". Proceedings of PCC Conference, IEEE, vol. 2, Osaka (JP), pp: 428-433.

[26] V.K. Ramachandaramurthy, A. Arulampalam, C. Fitzer, C. Zhan, M. Barnes and N. Jenkins, July 2004 "Supervisory control of dynamic voltage restorers "IEEE Proc.- Gener. Transm. Distrib. Vol. 151, No. 4, pp. 509-516.

[27] Benachaiba, C. and B. Ferdi, 2008. Voltage quality improvement using dynamic voltage restorer. Elect. Power Quality Utiliz. J., 14: 39-46. 